\title{
The Relationship Between Padi4 -94G/A Polymorphism and Rheumatoid Arthritis: A Meta- analysis in Multi Ethnic Groups
}

\section{Changchun Jian}

affiliated hospital of North Sichuan Medical College

Jingsong Pu (D PuJingsong2020@2980.com )

Affiliated Hospital of North Sichuan Medical College

\section{Research article}

Keywords: peptidylarginine deiminase 4, polymorphism, rheumatoid arthritis, meta-analysis

Posted Date: June 4th, 2020

DOI: https://doi.org/10.21203/rs.3.rs-32405/v1

License: (c) (1) This work is licensed under a Creative Commons Attribution 4.0 International License.

Read Full License 


\section{Abstract}

Background: A number of studies have reported the association between peptidylarginine deiminase 4 (PADI4) -94G/A polymorphisms and rheumatoid arthritis (RA) risk in different populations, however, the results remained inconclusive.

Objecitve: We therefore aim to address this association by performed an updated meta-analysis in multi ethnic groups.

Methods: The PubMed and Chinese related databases were searched up to January 2019. The strength of association between PADI-94G/A polymorphism and RA susceptibility was assessed with odds ratios (ORs) and 95\% confidence intervals (Cls).

Results: A total of 22 studies with 14514 RA cases and 21138 controls were finally included in the analysis. Six ethnic groups such as China, Japan, USA, UK, Sweden and Spain were contained. In the overall population, it revealed that PADI -94G/A polymorphism was significantly associated with an increased risk of RA. In the subgroup analyses by ethnicity, significant association was found in China as well as in Japan and USA.

Conclusions: This meta-analysis demonstrates that the PADI4 -94G/A polymorphisms may represent a significant risk factor for RA in China, in Japan and USA. Further studies are needed to clarify this finding, since most available studies were conducted among Chinese and Japanese in this study.

\section{Background}

Rheumatoid arthritis (RA) is one of the most common chronic systemic inflammatory diseases that cause joint destruction. In the United States, the overall prevalence of definite RA among adults is approximately 10 per 1,000 (1.0\%); rates for women are approximately 2.5 times higher than rates for men [1]. As the world's population ages and the proportion of people over the age of 60 increases, the prevalence of RA has also increased. The etiology and pathogenesis of RA is not fully understood. However, it has been hypothesized that the greatest impact of increased prevalence of RA is not due to the outcome of aging, but may be associated with genetic and environmental predisposing factors [2-4]. Peptidylarginine deiminase 4 (PADI4) -94G/A (rs2240340) has been identified as one of the RA susceptibility single nucleotide polymorphism, the results, however, are not frequently reproducible. In retrospect, individual studies with small sample sizes that are known to have low statistical power and yielded poor replication record. Moreover, this lack of reproducibility might also stem from discrepant lifestyle backgrounds. In order to reduce the influence of the diverse backgrounds, we performed a metaanalysis to assess the relationship between PADI -94G/A polymorphism and RA risk in multi ethnic groups respectively.

\section{Materials And Methods}




\section{Search strategy and selection criteria}

We performed the meta-analysis according to the guidelines of the PRISMA group. The PubMed and Chinese related databases were searched for studies on the relationship between PADI - 94G/A polymorphism and the risk of RA. The search keywords were (PADI4 or peptidylarginine deiminase 4 or $-94 G / A)$ and rheumatoid arthritis. The last search was updated on January, 2019. Additional records were identified by manual searching. Inclusion criteria: (1) studies on the association between PADI - 94G/A polymorphism and RA, (2) independent cohort or case-control studies in humans, (2) providing sufficient genetypes data in cases and controls. Exclusion criteria: (1) duplicate literatures, (2) incomplete data, (3) no controls, (4) review articles.

\section{Data Extraction}

Two reviewers extracted the data independently based on the inclusion criteria. Disagreements were resolved by a discussion. The following information was collected from each qualified study: first author's name, publication year, ethnicity, sample size, and available genotype information from PADI 94G/A polymorphism. Titles and abstracts of all potentially relevant articles were screened firstly. Full articles were then scrutinized if the title and abstract were ambiguous.

\section{Statistical analysis}

The strength of association between PADI - 94G/A polymorphism and RA susceptibility was assessed with odds ratios (ORs) and 95\% confidence intervals (Cls). The distributions of genotypes in controls were tested by Hardy-Weinberg equilibrium (HWE) using the Chi-square test. Four comparisons were performed: (1) allelic contrast, (2) contrast of homozygotes, (3) recessive, and (4) dominant models. Statistical heterogeneity was measured by Chi-squarebased Q-test. A fixed effects model was used when there was no heterogeneity among these studies; otherwise, the random-effects model was used. The significance of the pooled ORs were evaluated by a Z-test. Sensitivity analysis was performed by comparing the results of fixed-effects model and random-effects model. Begg's funnel plot and Egger's linear regression test were conducted to assess the publication bias. All statistical analyses were conducted using the Stata, version 12 (StataCorp LP, College Station, TX). A P value less than 0.05 was considered to be statistically significant.

\section{Results}

\section{Description of included studies}

Figure 1 illustrates the literature search process with a flow chart. Two hundred and twenty-five articles which examined the association between PADI polymorphisms and RA were identified. According to the inclusion and exclusion criteria, eighteen article (22 studies) with PADI - 94G/A and RA [5-22] were 
finally included in the analysis. The publication year of involved studies ranged from 2003 to 2014. In total, 14514 RA cases and 21138 controls were included in this meta-analysis. Six ethnic groups such as China, Japan, USA, UK, Sweden and Spain were included in our study. The pooled analysis was not performed for Sweden and Spain due to only one study respectively. The characteristics of these included studies are provided in Table 1. 
Table 1

Characteristics of studies included in the meta-analysis

\begin{tabular}{|c|c|c|c|c|c|c|}
\hline \multirow[t]{2}{*}{ References } & \multirow[t]{2}{*}{$\begin{array}{l}\text { publication } \\
\text { year }\end{array}$} & \multirow[t]{2}{*}{ Ethnicity } & \multirow[t]{2}{*}{$\begin{array}{l}\text { RA } \\
\text { number }\end{array}$} & \multirow[t]{2}{*}{$\begin{array}{l}\text { Controls } \\
\text { number }\end{array}$} & \multicolumn{2}{|c|}{$\begin{array}{l}\text { HWE in } \\
\text { controls }\end{array}$} \\
\hline & & & & & $x^{2}$ & $P$ \\
\hline Cui et al [5] & 2007 & China & 92 & 116 & 1.32 & 0.250 \\
\hline Feng et al [6] & 2009 & China & 115 & 106 & 3.14 & 0.076 \\
\hline Shi et al [7] & 2010 & China & 112 & 97 & 1.76 & 0.185 \\
\hline Chen et al [8] & 2011 & China & 378 & 204 & 0.93 & 0.334 \\
\hline Cui et al [9] & 2011 & China & 134 & 140 & 1.81 & 0.179 \\
\hline Xu et al [10] & 2011 & China & 130 & 130 & 1.95 & 0.162 \\
\hline Cheng et al [11] & 2012 & China & 324 & 695 & 0.10 & 0.751 \\
\hline Liu et al [12] & 2012 & China & 90 & 90 & 0.27 & 0.602 \\
\hline Li et al [13] & 2013 & China & 192 & 288 & 1.43 & 0.231 \\
\hline Du et al [14] & 2014 & China & 1216 & 1021 & 4.54 & 0.033 \\
\hline Suzuki et al [15] & 2003 & Japan & 822 & 646 & 0.05 & 0.829 \\
\hline Ikari et al [16] & 2005 & Japan & 1201 & 944 & 0.01 & 0.916 \\
\hline Takata et al [17] & 2008 & Japan & 946 & 503 & 0.53 & 0.466 \\
\hline Harney et al [20] & 2005 & UK & 100 & 94 & 0.00 & 0.989 \\
\hline Burr et al [21] & 2010 & UK & 3732 & 3039 & 1.29 & 0.256 \\
\hline Burr et al [21] & 2010 & UK & 1859 & 10599 & 0.01 & 0.929 \\
\hline Plenge et al [18] & 2005 & USA & 895 & 748 & 3.59 & 0.058 \\
\hline $\begin{array}{l}\text { Costenbader et al } \\
\text { [19] }\end{array}$ & 2008 & USA & 217 & 214 & 0.12 & 0.729 \\
\hline $\begin{array}{l}\text { Costenbader et al } \\
\text { [19] }\end{array}$ & 2008 & USA & 164 & 165 & 0.83 & 0.362 \\
\hline $\begin{array}{l}\text { Costenbader et al } \\
\text { [19] }\end{array}$ & 2008 & USA & 49 & 47 & 0.19 & 0.661 \\
\hline Plenge et al [18] & 2005 & Sweden & 1498 & 858 & 2.26 & 0.133 \\
\hline Martinez et al [22] & 2005 & Spain & 248 & 394 & 0.18 & 0.669 \\
\hline
\end{tabular}


The primary results of this meta-analysis on the association between PADI - 94G/A polymorphism and RA risk are shown in Table 2. In the overall population, it revealed that PADI - 94G/A polymorphism was significantly associated with an increased risk of RA in four models (Table 2, Fig. 2).

Table 2

Association of the PADI -94G/A polymorphism and RA susceptibility.

\begin{tabular}{|c|c|c|c|c|c|}
\hline \multicolumn{2}{|l|}{ Analysis model } & \multirow{2}{*}{$\begin{array}{l}\mathbf{n} \\
22\end{array}$} & \multirow{2}{*}{$\begin{array}{l}\mathrm{OR}_{\mathrm{r}}(95 \% \mathrm{Cl}) \\
1.16(1.09-1.24)\end{array}$} & \multirow{2}{*}{$\begin{array}{l}\mathrm{OR}_{\mathrm{f}}(95 \% \mathrm{Cl}) \\
1.10(1.07-1.14)\end{array}$} & \multirow{2}{*}{$\begin{array}{l}P_{h} \\
0.000\end{array}$} \\
\hline A vs. G & Total analysis & & & & \\
\hline & China & 10 & $1.24(1.14-1.35)$ & $1.24(1.15-1.34)$ & 0.371 \\
\hline & Japan & 3 & $1.28(1.17-1.39)$ & $1.28(1.18-1.38)$ & 0.342 \\
\hline & UK & 3 & $1.00(0.95-1.05)$ & $1.00(0.95-1.05)$ & 0.510 \\
\hline & USA & 4 & $1.18(1.05-1.32)$ & $1.18(1.05-1.32)$ & 0.414 \\
\hline \multirow[t]{5}{*}{ AA vs. GG } & Total analysis & 22 & $1.33(1.18-1.51)$ & $1.21(1.14-1.30)$ & 0.001 \\
\hline & China & 10 & $1.49(1.28-1.73)$ & $1.49(1.28-1.73)$ & 0.495 \\
\hline & Japan & 3 & $1.64(1.39-1.94)$ & $1.64(1.39-1.94)$ & 0.396 \\
\hline & UK & 3 & $1.03(0.93-1.13)$ & $1.03(0.93-1.13)$ & 0.458 \\
\hline & USA & 4 & $1.35(1.08-1.69)$ & 1.35 (1.08-1.69 & 0.498 \\
\hline \multirow[t]{5}{*}{ AA vs. $G G+G A$} & Total analysis & 22 & $1.15(1.07-1.24)$ & $1.13(1.07-1.20)$ & 0.229 \\
\hline & China & 10 & $1.19(1.04-1.36)$ & $1.19(1.04-1.35)$ & 0.916 \\
\hline & Japan & 3 & $1.42(1.22-1.65)$ & $1.42(1.22-1.65)$ & 0.613 \\
\hline & UK & 3 & $1.06(0.96-1.17)$ & $1.06(0.97-1.15)$ & 0.326 \\
\hline & USA & 4 & $1.18(0.97-1.45)$ & $1.18(0.97-1.45)$ & 0.537 \\
\hline \multirow[t]{5}{*}{$A A+G A$ vs. GG } & Total analysis & 22 & $1.12(1.13-1.40)$ & $1.14(1.09-1.20)$ & 0.000 \\
\hline & China & 10 & $1.50(1.25-1.81)$ & $1.45(1.29-1.62)$ & 0.042 \\
\hline & Japan & 3 & $1.36(1.21-1.54)$ & $1.36(1.21-1.53)$ & 0.360 \\
\hline & UK & 3 & $0.97(0.90-1.04)$ & $0.97(0.90-1.04)$ & 0.489 \\
\hline & USA & 4 & $1.22(0.99-1.52)$ & $1.27(1.08-1.50)$ & 0.272 \\
\hline
\end{tabular}

\section{Padi - 94g/a Polymorphism With Ra In China And Japan}


Ten studies including 2783 cases and 2887 controls identified an association between the PADI - 94G/A polymorphism and RA risk in China [5-14], as well as three studies including 2969 cases and 2093 controls in Japan [15-17]. It revealed that PADI - 94G/A polymorphism was significantly associated with an increased risk of RA both in China and Japan among all analysis models (Table 2, Figs. 2).

\section{Padi - 94g/a Polymorphism And Ra In Usa}

Four studies including 1325 cases and 1174 controls identified an association between the PADI - 94G/A polymorphism and RA risk in USA [18-19]. Meta-analysis revealed that PADI - 94G/A polymorphism was significantly associated with an increased risk of RA in allelic contrast, in homozygotes and dominant models (Table 2, Figs. 2).

\section{Padi - 94g/a Polymorphism And Ra In Uk}

Three studies determined the relationship between PADI - 94G/A polymorphism and RA risk in UK [2021]. The total sample size for patients with RA and controls was 5691 and 13732, respectively. It revealed that PADI - 94G/A polymorphism was not associated with RA in UK (Table 2, Figs. 2).

\section{Sensitivity Analysis And Publication Bias Diagnosis}

To evaluate the sensitivity of this meta-analysis, we compared the consistency between fixed-effects model and random-effects model. All the analysis results were not materially altered except the dominant model in USA (Table 2). Hence, the pooled results in this meta-analysis are relatively stable and credible. The Begg's funnel plot and Egger's test were performed to evaluate the publication bias. As showed in Fig. 3, the shape of the funnel plot did reveal obvious asymmetry. Similarly, the Egger's test showed that there was obvious publication bias in all the included studies $(t=4.29, p=0.000$, Fig. 4$)$.

\section{Discussion}

Although the multifactorial nature of RA is well known, genetic factors are considered to be strong determinants of these diseases, thus encouraging researchers to search for the responsible genes. PADI4 has been implicated in the pathogenesis, activity and severity of RA [23-24]. Since the first positive association between PADI - 94G/A and RA was reported in a Japanese population [15], a number of studies have reported the association between PADI - 94G/A polymorphisms and RA risk in different populations. Till now, there are several published meta-analyses regarding PADI4 -94G/A polymorphisms and RA risk [25-30]. Of these, two meta-analyses reported that there was significant association between PADI4 -94G/A polymorphism and RA risk both in Asian and European population [26, 28], while two metaanalyses reported that there was significant association only in Asian individuals [27, 29]. However, only one meta-analysis was conducted in a separate ethnic group [30]. Therefore, we performed this meta- 
analysis to assess the relationship between PADI - 94G/A polymorphism and RA risk in multi ethnic groups respectively.

Our meta-analysis involved 22 studies with 14514 RA cases and 21138 controls. The results showed that a significantly elevated risk of RA was associated with all variants of PADI4 -94G/A in the overall analysis. In the subgroup analyses by ethnicity, significant association was found in China as well as in Japan and USA. Compared with the previous meta-analyses [25-30], the current study involved more research in multi ethnic groups. And the effects of gene-environment interactions with respect to RA risk were also conducted by each separate ethnic group analysis. The sensitivity analysis confirmed the reliability and stability of the meta-analysis. Therefore, the findings from our meta-analysis provide a strong evidence for the association between PADI4 -94G/A polymorphism and RA in the three contries. It also indicated that the relationship between PADI4 -94G/A polymorphism and RA might be susceptible in different ethnicity.

Nevertheless, there are several limitations to this meta-analysis. First, because the papers searched in our study were limited to those openly published, it is possible that some non-published literature that may meet the inclusion criteria were missed. Second, non-English/Chinese articles and databases were not reviewed in our meta-analysis, thus might introduce some bias. Third, due to the relative small sample size of some studies or lack of necessary information, we did not perform further subgroup analyses. Finally, publication bias existed in our analysis, which indicated that other language studies should be included.

In conclusion, this meta-analysis demonstrates that the PADI4 -94G/A polymorphisms may represent a significant risk factor for RA in China, in Japan and USA. Ethnicity seems to play an important role in the genetic association of the disease. Further studies are needed to clarify this finding, since most available studies were conducted among Chinese and Japanese in this meta-analysis.

\section{Declarations}

\section{Ethics approval and consent to participate}

Not applicable.

\section{Consent for publication}

Not applicable.

\section{Availability of data and materials}

The authors agree to share the data and materials of this paper. 


\section{Competing interests}

The authors report no conflicts of interest.

\section{Funding}

None.

\section{Authors' contributions}

We declare that all the listed authors have participated actively in the study and all meet the requirements of the authorship. CJ designed the study and wrote the protocol and performed research/study, JP contributed important reagents, JP and CJ managed the literature searches and analyses, JP undertook the statistical analysis and wrote the first draft of the manuscript.

\section{Acknowledgements}

None.

\section{References}

1. Lawrence RC, Helmick CG, Arnett FC, et al. Estimates of the prevalence of arthritis and selected musculoskeletal disorders in the United States. Arthritis Rheum. 1998;41:778-99.

2. Hochberg MC, Spector TD. Epidemiology of rheumatoid arthritis: update. Epidemiol Rev. 1990;12:247-52.

3. Turesson C, Matteson EL. Genetics of rheumatoid arthritis. Mayo Clin Proc. 2006;81(1):94-101.

4. Ghelani AM, Samanta A, Jones AC, Mastana SS. Association analysis of TNFR2, VDR, A2M, GSTT1, GSTM1, and ACE genes with rheumatoid arthritis in South Asians and Caucasians of East Midlands in the United Kingdom. Rheumatol Int, 2011, 31(10), 1355-1361.

5. Cui LF, Yang WH, Song HC, Shu R, Han YX, Liu YY, et al. Association of polymorphism of peptidylarginine deiminase 4 gene and rheumatoid arthritis in Han Population. Chin J Allergy Clin Immunol. 2007;1:158-62. (in Chinese).

6. Feng ZJ, Liang Y, Wen HF, Niu YL. Study on single nucleotide polymorphism of PADI4_94 gene in Chinese Han people of Hebei Province. Chin J Clin Lab Sci. 2009;27:97-9. (in Chinese).

7. Shi HX, Qian L, Li XP, Li XM, Wang GS, Zhang H. Association of polymorphism of peptidylarginine deaminase-4 gene and rheumatoid arthritis. Chin J Rheumatol. 2010;14:336-9. (in Chinese).

8. Chen R, Wei Y, Cai Q, Duan S, Ren D, Shen J, et al. The PADI4 gene does not contribute to genetic susceptibility to rheumatoid arthritis in Chinese Han population. Rheumatol Int. 2011;31:1631-4. 
9. Cui LF, Yuan W, Yang WH, Shu R, Song HC, Han YX, et al. Association of polymorphism of peptidylarginine deiminase 4 (PADI4) gene with rheumatoid arthritis and anti-cyclic citrullinated peptide antibody. Chin J Basic Med Tradit Chin Med. 2011;17:630-2. (article in Chinese).

10. Xu BS, Shao FM, Sun CY, Qin WS, Hu H. Association of peptidylarginine deiminase 4-94 and 104 single nucleotide polymorphisms with rheumatoid arthritis. Chin J Prev Contr Chron Dis. 2011;19:489-91. (In Chinese).

11. Cheng J, Zhang H, Zhuang C, Liu R. Peptidylarginine deiminase type 4 and methyl-CpG binding domain 4 polymorphisms in Chinese patients with rheumatoid arthritis. J Rheumatol. 2012;39:115965.

12. Liu J, Yang FM, Zhang PL, Li R, Wang YJ. Association of peptidylarginine deiminase 4 single nucleotide polymorphisms with rheumatoid arthritis in Chinese Han, Zang and Hui populations. Chin J Gerontol. 2012;32:3881-3. (in Chinese).

13. Li Q, Lin KQ, Li Q, Wang J, Yu J, Yu L, et al. Association of polymorphisms of PTPN22 and PADI4 genes with rheumatoid arthritis in Yunnan. Zhonghua Yi Xue Yi Chuan Xue Za Zhi. 2013;30:111-5. (article in Chinese).

14. Du Y, Liu X, Guo JP, Liu X, Li R, Zhao Y, Liu X, Li MH, Li ZG. Association between PADI4 gene polymorphisms and anti-cyclic citrullinated peptide antibody positive rheumatoid arthritis in a large Chinese Han cohort. Clin Exp Rheumatol. 2014;32(3):377-82.

15. Suzuki A, Yamada R, Chang X, Tokuhiro S, Sawada T, Suzuki M, et al. Functional haplotypes of PADI4, encoding citrullinating enzyme peptidylarginine deiminase 4 , are associated with rheumatoid arthritis. Nat Genet. 2003;34:395-402.

16. Ikari K, Kuwahara M, Nakamura T, Momohara S, Hara M, Yamanaka H, et al. Association between PADI4 and rheumatoid arthritis: a replication study. Arthritis Rheum. 2005;52:3054-7.

17. Takata $Y$, Inoue H, Sato A, Tsugawa K, Miyatake K, Hamada D, et al. Replication of reported genetic associations of PADI4, FCRL3, SLC22A4 and RUNX1 genes with rheumatoid arthritis: results of an independent Japanese population and evidence from meta-analysis of East Asian studies. J Hum Genet. 2008;53:163-73.

18. Plenge RM, Padyukov L, Remmers EF, Purcell S, Lee AT, Karlson EW, et al. Replication of putative candidate-gene associations with rheumatoid arthritis in $>4,000$ samples from North America and Sweden: association of susceptibility with PTPN22, CTLA4, and PADI4. Am J Hum Genet. 2005;77:1044-60.

19. Costenbader KH, Chang SC, De Vivo I, Plenge R, Karlson EW. Genetic polymorphisms in PTPN22, PADI-4, and CTLA-4 and risk for rheumatoid arthritis in two longitudinal cohort studies: evidence of gene-environment interactions with heavy cigarette smoking. Arthritis Res Ther. 2008;10:R52.

20. Harney SM, Meisel C, Sims AM, Woon PY, Wordsworth BP, Brown MA. Genetic and genomic studies of PADI4 in rheumatoid arthritis. Rheumatology. 2005;44:869-72.

21. Burr ML, Naseem H, Hinks A, Eyre S, Gibbons LJ, Bowes J, et al. PADI4 genotype is not associated with rheumatoid arthritis in a large UK Caucasian population. Ann Rheum Dis. 2010;69:666-70. 
22. Martinez A, Valdivia A, Pascual-Salcedo D, Lamas JR, Ferna'ndez-Arquero M, Balsa A, et al. PADI4 polymorphisms are not associated with rheumatoid arthritis in the Spanish population. Rheumatology. 2005;44:1263-6.

23. Suzuki T, Ikari K, Yano K, et al. PADI4 and HLA-DRB1 Are genetic risks for radiographic progression in RA patients, independent of ACPA status: Results from the IORRA Cohort Study. PLoS One. 2013;8:e61045.

24. Ceccarelli F, D'Alfonso S, Perricone $\mathrm{C}$, et al. The role of eight polymorphisms in three candidate genes in determining the susceptibility, phenotype, and response to anti-TNF therapy in patients with rheumatoid arthritis. Clin Exp Rheumatol. 2012;30:939e942.

25. Lee YH, Rho YH, Choi SJ, Ji JD, Song GG. PADI4 polymorphisms and rheumatoid arthritis susceptibility: a meta-analysis. Rheumatol Int. 2007;27:827-33.

26. Takata Y, Inoue H, Sato A, Tsugawa K, et al. Replication of reported genetic associations of PADI4, FCRL3, SLC22A4 and RUNX1 genes with rheumatoid arthritis: results of an independent Japanese population and evidence from meta-analysis of East Asian studies. J Hum Genet. 2008;53:163-73.

27. Hou S, Gao GP, Zhang XJ, Sun L, et al. PADI4 polymorphisms and susceptibility to rheumatoid arthritis: a meta-analysis. Mod Rheumatol. 2013;23:50-60.

28. Iwamoto T, Ikari K, Nakamura T, Kuwahara M, Toyama Y, Tomatsu T, Momohara S, Kamatani N. Association between PADI4 and rheumatoid arthritis: a meta-analysis. Rheumatology. 2006;45(7):804-7.

29. Yang XK, Liu J, Liu J, Liang Y, Xu WD, Leng RX, Pan HF, Ye DQ. Associations Between PADI4 Gene Polymorphisms and Rheumatoid Arthritis: An Updated Meta-analysis. Arch Med Res. 2015;46(4):317-25.

30. Chang HX. Association between the PADI4 -94G/A polymorphism and rheumatoid arthritis: a metaanalysis in the Chinese population. Genet Mol Res, 2016, 15(1).

\section{Figures}


225 records identified

through database searching

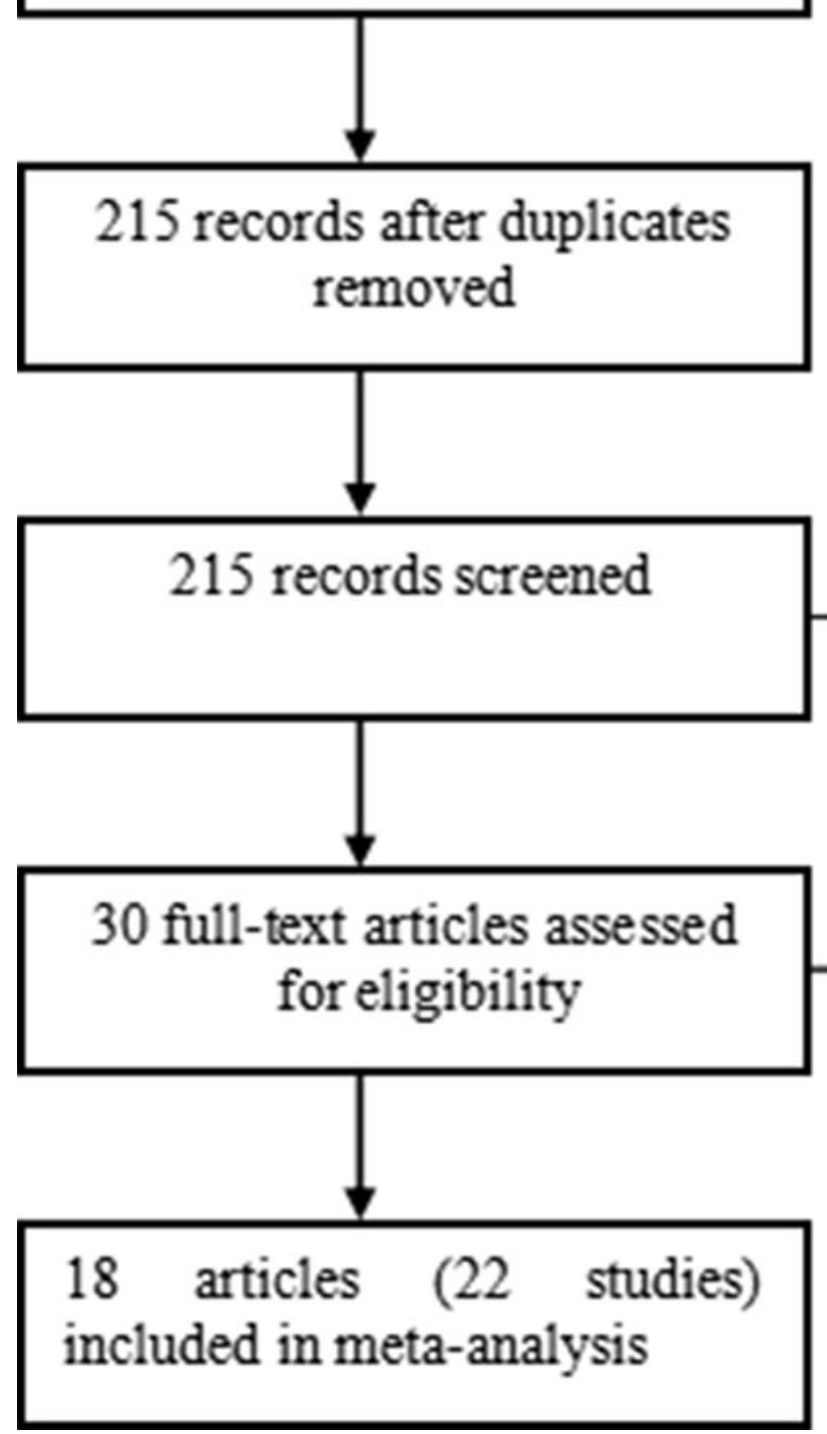

185 records excluded:

83 obviously irrelevant studies

76 reviews or meta-analyses

26 study not conducted in human
12 full-text articles excluded:

6 insufficient genotyping data

5 reduplicate studies

1 other genetype

\section{Figure 1}

Flow diagram of the literature search. 
Study

ID

OR $(95 \% \mathrm{Cl}) \quad \stackrel{\%}{\text { Weight }}$

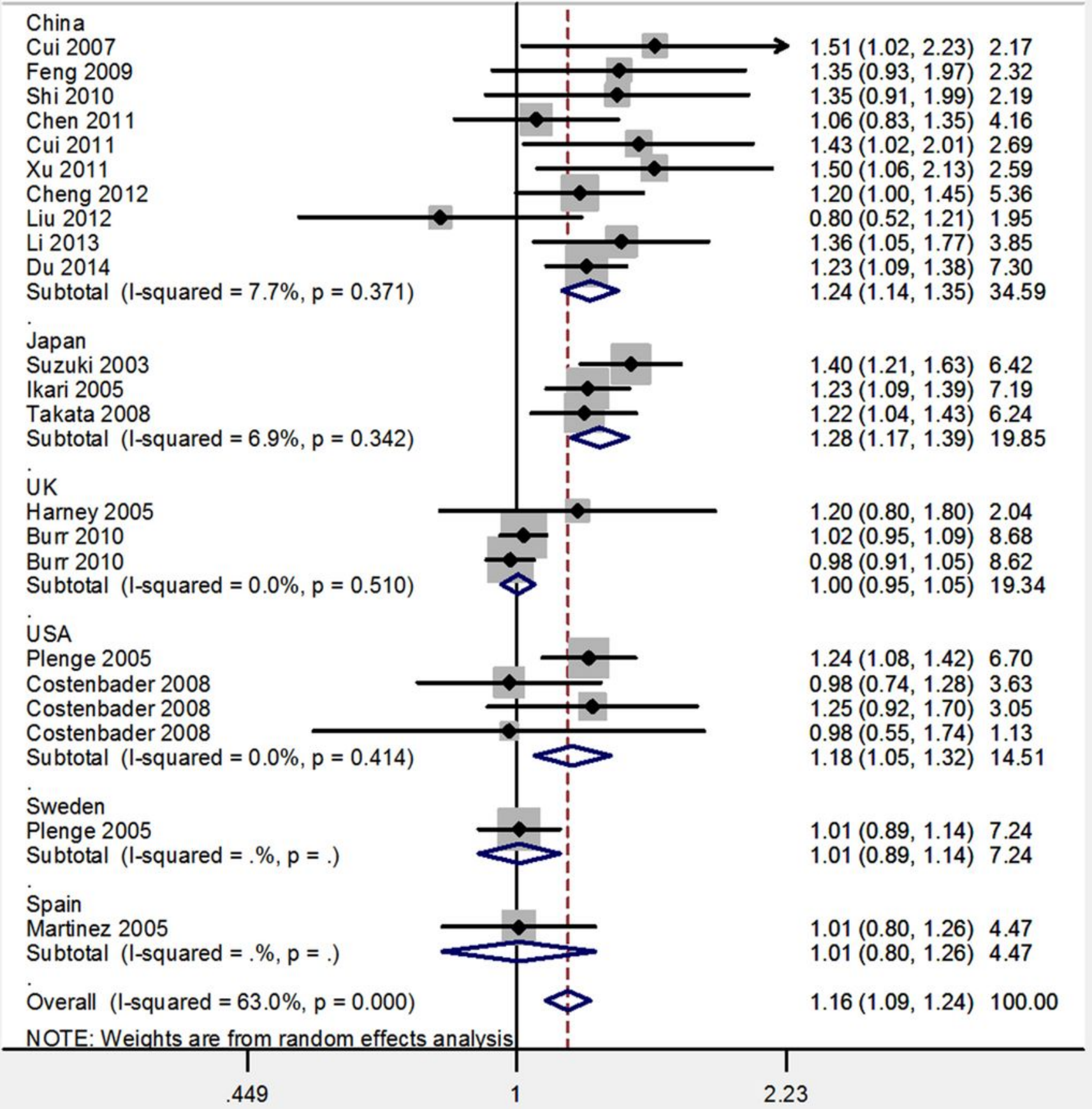

Figure 2

The forest plots of all selected studies on the association between PADI-94G/A polymorphism and RA susceptibility under allele model. 
Funnel plotwith pseudo $\$ 6 \%$ confidence limits

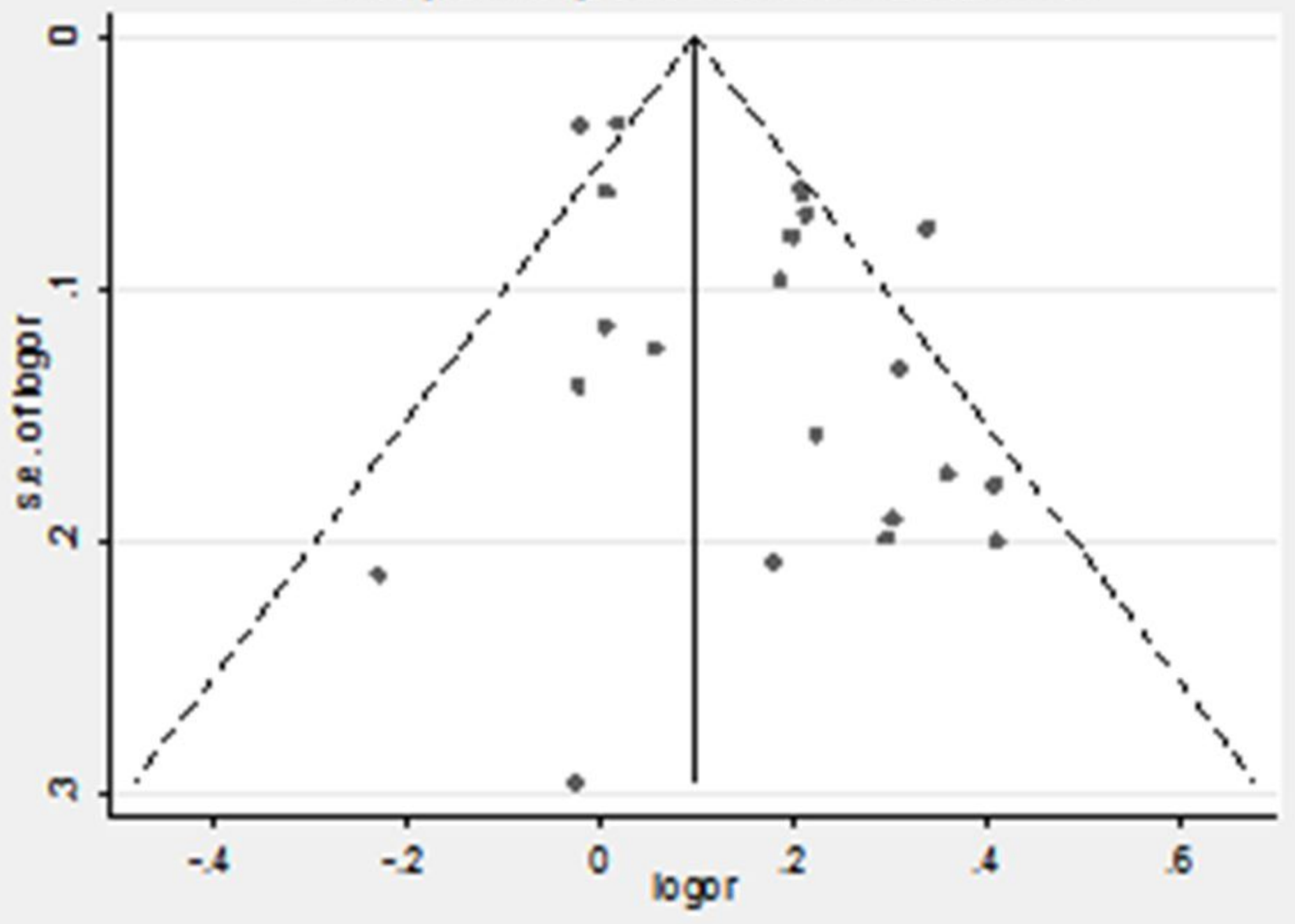

Figure 3

Publication bias assessment with Begg's funnel plot. 
Egger's publication bias plot

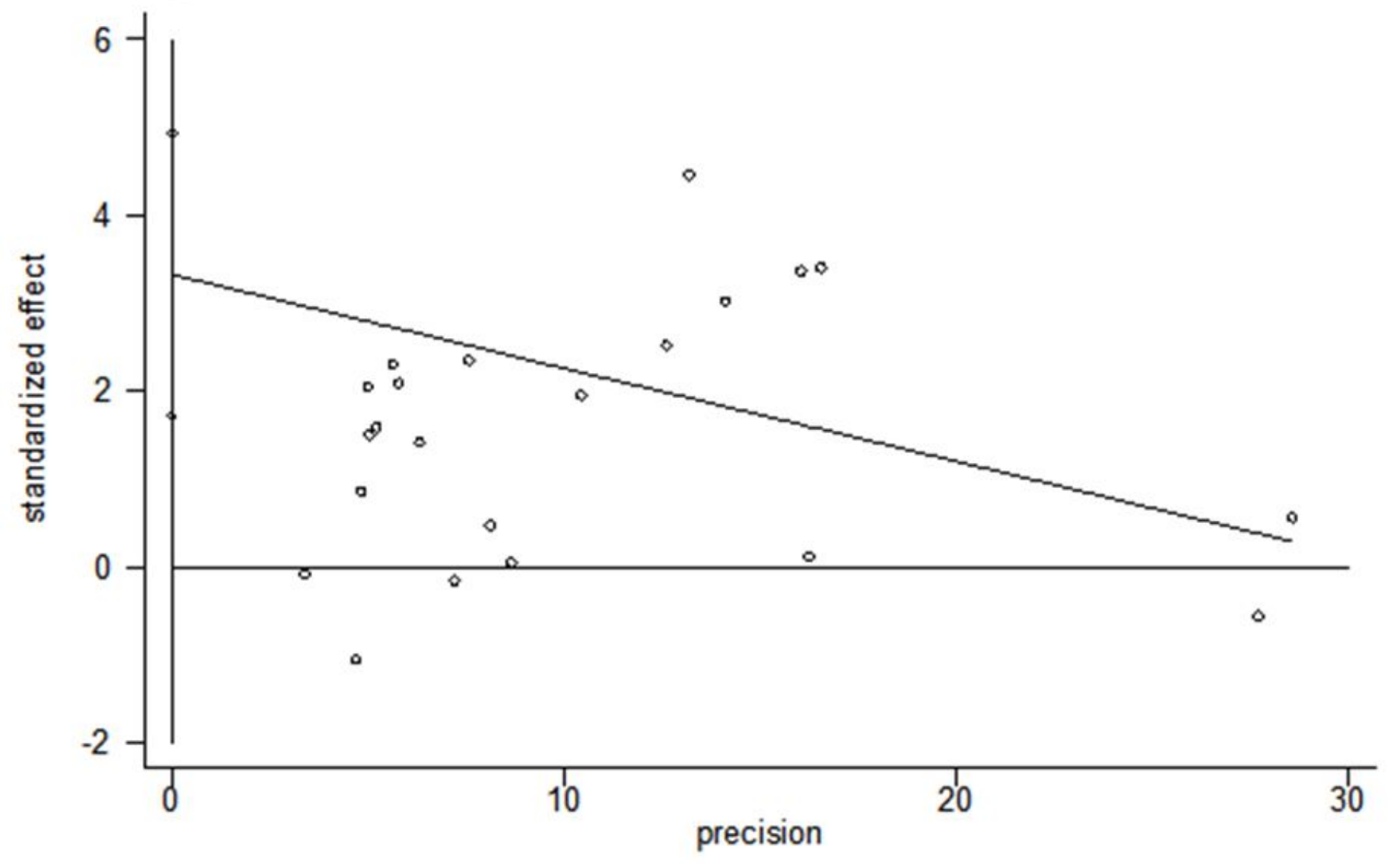

Figure 4

Egger's linear regression. 